\title{
Análise comparativa do processo de transferência de terras públicas para o domínio privado no Brasil e EUA: uma abordagem institucionalista ${ }^{1}$
}

Sebastião Neto Ribeiro Guedes ${ }^{2}$

Resumo: O artigo discute o papel das instituições - legislações sobre a terra e da forma do Estado Nacional - na transformação do domínio público das terras em propriedade privada no Brasil e nos EUA. Ele mostra os diferentes percursos, objetivos e instrumentos utilizados para este propósito pelos dois países, assim como seus resultados em termos de estrutura fundiária na agricultura.

Palavras-chave: política de terras; estrutura fundiária; desenvolvimento agrícola; economia institucional.

\section{A comparative analysis of land transfer from public to private ownership in Brazil and the USA: an institutional approach}

\begin{abstract}
This paper discusses the role of the institutions - the land law and the organization of the State - in the constitution of the private property in Brazil and USA in the $19^{\text {th }}$ century. It also analyses the results of the process on land structure and agriculture.
\end{abstract}

Key words: Land policy; land property structure; agriculture development; institutional economics.

JEL: Ko; No; N5

\footnotetext{
$1 \mathrm{O}$ autor agradece as preciosas sugestões do parecerista anônimo, mas se responsabiliza integralmente pela forma e conteúdo desse texto.

2 Doutor em Economia pela Unicamp e professor e coordenador do curso de Ciências Econômicas da Universidade Metodista de Piracicaba (UNIMEP). E-mail: sebaneto@unimep.br
} 


\section{Introdução}

Este texto pretende comparar as políticas de terra do Brasil e dos EUA no século XIX, centrando-se no papel das instituições na constituição da propriedade privada da terra. Embora possuíssem algumas características comuns (ex-colônias, grande dimensão territorial, presença do trabalho escravo, etc), os dois países experimentaram caminhos (e também resultados) distintos na tarefa de transferir terras do domínio público para o privado. Disso resultaram padrões diferentes de democratização do acesso à terra, estruturas fundiárias díspares, e papéis diversos para a agricultura familiar na dinâmica das atividades agropecuárias. O texto reconhece a importância do grau de desenvolvimento do capitalismo na explicação dessas discrepâncias ${ }^{3}$, mas busca agregar-lhe como hipótese adicional a natureza das instituições e sua (in)capacidade de impor-se, regulando, de alguma maneira, o acesso, uso e a propriedade da terra. Dentre as instituições serão referidas aqui as legislações sobre a terra (e as organizações encarregadas de implementá-las) e a forma de organização do Estado característica de cada país. Acredita-se que sua origem, formato e modo de funcionamento auxiliam grandemente no entendimento das especificidades que caracterizaram a constituição da propriedade privada nos dois países. Sendo assim, o texto divide-se em três partes. Na primeira apresentam-se rapidamente as referências teóricas que sustentam o argumento de que a natureza das instituições e do tipo de sua interação é relevante para explicar as diferenças nas políticas de terras e nas estruturas fundiárias capitalistas. Na segunda parte analisam-se as políticas de terra dos EUA ao longo do século XIX, buscando identificar sua lógica, forma de implementação, resultados e a relevância das instituições. A última versará sobre as políticas de terras no Brasil, tendo como foco da análise a Lei de Terras de 1850, bem como o papel da mudança na forma de organização do Estado de unitária para federada.

\section{Instituições e ambiente institucional}

A relevância das instituições na explicação dos fenômenos socioeconômicos tem despertado crescente interesse entre os economistas, apesar de que, conforme observou Baslé (1993), a análise das

\footnotetext{
3 Esse ponto de vista está presente, por exemplo, em João A. de Paula (2002: 25). Para este autor as diferenças entre as filosofias que presidiram a Lei de Terras no Brasil e o Homestead Act, nos EUA, refletem, no fundamental, o lugar dos interesses especificamente capitalistas no interior do aparelho do Estado, e no conjunto da sociedade dos dois países. Isto é, enquanto no Brasil o Estado e a sociedade ainda estavam submetidos a um senhorio escravista, mercantilista e exportador, cópia "nacional" dos velhos interesses colonialistas, nos EUA, os interesses do grande capital já eram hegemônicos, o que seria definitivamente demonstrado pela vitória do Norte na Guerra Civil de 1861-65. Perspectiva semelhante já havia sido apresentada por Emília Costa (1987).
} 
instituições e o uso do adjetivo institucional para caracterizar uma teoria ou abordagem não são novas em Economia. De uma maneira genérica, são institucionalistas aqueles economistas para os quais as "instituições importam". Mais especificamente, a expressão vem sendo empregada para identificar aqueles economistas que, insatisfeitos com a teoria neoclássica instituída, procuram construir um caminho alternativo, tendo como eixo a noção de instituição.

Num artigo no qual faz um balanço dos resultados alcançados pela pesquisa institucionalista recente, Williamson (2000) constata que apesar do enorme progresso no estudo das instituições ainda predomina muita ignorância sobre elas. Isto faz com que seja impossível, pelo menos no momento, uma teoria unificada das instituições. Sendo assim, ele recomenda que "enquanto aguardamos uma teoria unificada, devemos aceitar o pluralismo ${ }^{4}$."

Uma avaliação dos resultados da pesquisa institucionalista indica que ela tem se desenvolvido em três níveis: o primeiro, mais geral e estável, é chamado de embeddedness, e inclui o estudo de instituições formais como as religiões e o Estado, e informais, como as normas, as tradições e os costumes. Pesquisas nas áreas de história econômica e da sociologia têm privilegiado esta dimensão das instituições e seus mecanismos de conservação/transformação. A segunda dimensão, chamada de ambiente institucional, estuda as regras formais que fazem a mediação nas relações que os agentes estabelecem entre si. Dada sua natureza, essas instituições são mais propensas que as anteriores a mudanças, que ocorrem na legislação, no sistema judiciário, na burocracia governamental e naquelas instituições que implementam os direitos de propriedade. Nesse nível é possível identificar arranjos institucionais que economizam: aqueles que introduzem as regras "corretas" do jogo. A vertente principal que está à frente nesse tipo de estudo é a economia dos direitos de propriedade ${ }^{5}$. A terceira dimensão, chamada de governança ou economia dos custos de transação, lida com a questão dos custos associados às transações econômicas. Estas envolvem ativos e potenciais de comportamento humanos que, combinados de maneira específica, respondem pelas estruturas de governança. As instituições que emergem buscam então propósitos de economizar os custos de transação. Essa dimensão, liderada por Coase e Williamson, vem produzindo um conjunto de pesquisas empíricas de recorte setorial e individual bastante

\footnotetext{
$4 \mathrm{O}$ mote do pluralismo parece-nos uma alternativa não apenas momentânea (enquanto se aguarda uma teoria unificada), mas uma afirmação metodológica que pode oferecer um campo profícuo para o debate e desenvolvimento teórico em Economia.

5 Um balanço do "estado da arte" da teoria dos direitos de propriedade pode ser encontrado em Cole e Grossman (2002).
} 
rico. Um esforço de articular os dois últimos níveis vem sendo feito, em particular por Williamson ${ }^{6}$.

Optou-se aqui por utilizar o modelo apresentado por Fleming $(1999)^{7}$,que, adequadamente adaptado, pode auxiliar na compreensão do papel das instituições no desenho e aplicação das políticas de terras. O modelo de Fleming é ilustrado na Figura 1 e apresenta as instâncias das leis, normas e mercado e sua influência sobre o comportamento econômico. Essas relações são de dupla mão: das instâncias para o indivíduo e deste para aquelas. Todavia, as capacidades individuais de influenciar as três instâncias são bastante pequenas ${ }^{8}$. De outro lado, as instâncias possuem capacidade significativa de determinar o comportamento individual, além de interagir e condicionar-se mutuamente. As leis (instituições formais) são constrangimentos objetivos que influenciam o comportamento ao apresentar as sanções devidas no caso de sua não observância. As normas (instituições informais) são constrangimentos sobre o comportamento originado de pressão social ou comunitária, cuja força reside na ameaça de exclusão do convívio social ou perda de respeitabilidade/status que pode recair sobre um membro que quebre o comportamento esperado pela norma. O mercado é entendido como um tipo de instituição no interior da qual o mecanismo de preços constrange e orienta o comportamento individual.

\footnotetext{
6 Em parte como resposta às críticas sobre o efeito teórico do recorte microanalítico de Williamson. Em especial Pitelis (1994) e Bouvier-Patron (1993) apontaram que a opção por este recorte reforça o caráter "circulacionista" da análise de Williamson, pois esta propõe uma separação analítica entre produção (custos de produção) e transação (custos de transação) que confere total autonomia às transações em termos de explicação das inovações organizacionais. O problema aí é que as instituições "externas" ao mercado podem promover incentivos capazes de influenciar os custos de produção das organizações, os quais têm efeito indireto sobre os custos de transação. Mais ainda, o ambiente institucional, em muitos casos, determina o próprio caráter de especificidade de vários ativos, demonstrando que nem sempre ele é intrínseco e independente. De outro lado, ao tomar como dado o ambiente institucional, fica difícil compreender o papel que sobre ele jogam as inovações verificadas nas instituições do mercado e da firma.

7 Embora a reflexão deste autor possa ser enquadrada na segunda dimensão da abordagem institucionalista, ele não é um teórico dos direitos de propriedade, no sentido estrito do termo.

8 Embora no modelo original o indivíduo tenha menor capacidade de influenciar as instâncias institucionais, não se deve desconsiderar esse papel quando o comportamento individual articulase e materializa-se em ação coletiva. Nesse caso, ela pode resultar em alterações em um (ou mais) dos parâmetros e na sua interação com os demais, com efeitos diferentes daqueles inicialmente imaginados. Em certa medida, os casos analisados nas próximas seções corroboram esse ponto de vista.
} 
FIGURA 1. TIPOS DE INSTITUIÇÕES E SUA RELAÇÃO COM O COMPORTAMENTO ECONÔMICO

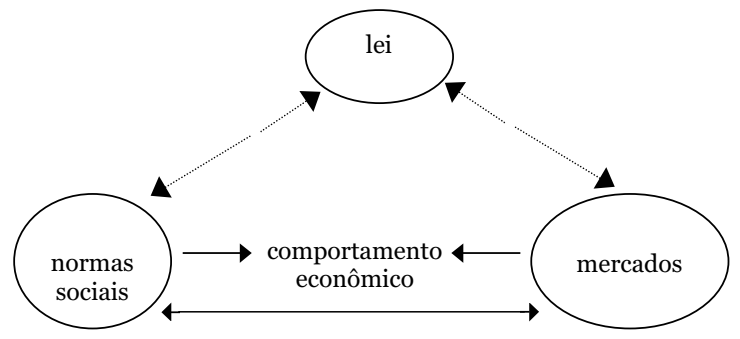

FONTE: Fleming 1999:165

As leis, normas e mercados somente realizam seu papel de constrangimentos quando são subjetivamente efetivas, ou seja, quando o indivíduo consciente ou inconscientemente as reconhece como um constrangimento. Vale dizer que as instituições nem sempre "funcionam" como orientador e constrangedor de comportamentos, o que coloca em xeque qualquer pretensão de otimização dessas instituições. Os crimes, as burlas, o desrespeito às instituições são todos exemplos da incapacidade delas serem subjetivamente apropriadas pelos indivíduos. Por que isto acontece? A resposta de Fleming, baseada na resenha de estudos de caso feitos por vários autores, é a de que é o tipo de relacionamento, articulação e interação entre as instâncias que determina sua efetividade sobre o comportamento individual.

Há casos em que as normas e leis são cooperativas, complementando-se e reforçando-se mutuamente. Nesses casos, as instâncias promovem a acumulação de capital físico e social de uma comunidade, contribuindo para o seu desenvolvimento e bem-estar. Há outros em que as leis não conseguem ser aplicadas porque são conflitivas com as normas prevalecentes, resultando daí uma menor acumulação de capital físico e social, com reflexos negativos sobre o desenvolvimento econômico e o bemestar. Acredita-se que os casos que serão analisados a seguir ilustram os dois tipos de arranjos possíveis entre as instâncias institucionais.

\section{Política de terras nos EUA}

A política de terras dos EUA teve duas fases distintas, que refletiram os dilemas de constituição e afirmação do Estado Nacional e a expansão e consolidação do capitalismo norte-americano. A primeira, que vai de 1776 a 1862, é denominada aqui de política de terras com ênfase na receita pública, cujas características principais foram a 
institucionalização da propriedade privada plena da terra e a utilização do mercado como instrumento de política de disponibilização das terras públicas; a segunda, que tem início em 1862, com a aprovação da Homestead Act ${ }^{9}$, é aqui denominada de política de terras distributivista, cuja característica foi a cessão gratuita de terras públicas a quem nela desejasse cultivar. A passagem de uma para a outra refletiu um certo compromisso entre a expansão do capitalismo, com sua tendência a tudo transformar em mercadoria, inclusive a terra, e o ideal jeffersoniano de uma sociedade agrária de pequenos fazendeiros independentes.

\subsection{A política de terras com ênfase na receita pública}

Entre os principais analistas da política de terras norte-americana é praticamente unânime o ponto de vista de que a política de terras entre 1776 e 1862 foi motivada pelo interesse do Estado em auferir receita através da venda das terras públicas. A necessidade de enfrentar a crise financeira deixada pela Guerra de Independência e as novas despesas que a União assumiu (os custos da burocracia nacional, os encargos e indenizações prometidas aos combatentes da Revolução) fizeram vitoriosa a visão de Hamilton, primeiro secretário do Tesouro, de fortalecer as finanças públicas da União através da venda de terras. Não é de surpreender, portanto, que essa política utilizasse o mercado como seu instrumento. Essa vitória - parcial e momentânea - não sufocou as aspirações daqueles que, como Jefferson, se opunham à política de venda de terras, defensores que eram de uma economia agrária baseada na pequena propriedade familiar e de uma política de terras aberta. A tensão entre essas duas visões sobre como dispor do domínio público permeou todo esse período da política de terra.

No subperíodo compreendido entre 1776 e 1812, a política de terras era muito bem definida. O Estado, como já anteriormente mencionado, decidiu transferir o domínio público das terras para o domínio privado através do mercado, vendendo-as em leilão público. Essa orientação de política exigiu do Estado a definição prévia do domínio público, sua extensão e status. Tratou-se, portanto, de definir antes de tudo os direitos de propriedade das terras do Estado. A razão é mais ou menos óbvia: para disponibilizar terras, o Estado precisava, antes, identificar quais eram as suas terras, sob o risco de vender o que não lhe pertencia.

Nesse sentido, o governo central, ao longo do período, tomou várias medidas. Primeiro foram negociadas as terras indígenas, em tratados 
semelhantes aos feitos com nações estrangeiras. A maioria foi comprada dos índios por preços que variavam de 1 centavo a 1 dólar o acre. Segundo Gates (1989), por volta de 1820 cerca de 191.978 .000 acres tinham sido comprados deles.

Depois dos índios, eram confirmados direitos de propriedade de doações feitas por governos anteriores a agentes privados, bem como aqueles dos colonos situados em áreas recém-adquiridas que não tinham título de propriedade (de 400 a 640 acres). Em seguida, antecipando a demanda, a terra era demarcada em distritos, seções e subseções. No momento julgado adequado, as terras eram divulgadas para a venda em leilões públicos e vendidas ao preço mais alto a partir do preço mínimo: dois dólares o acre de 1800 a 1820 e um dólar e vinte e cinco centavos após esta data.

A opção pela via do mercado implicou o enfrentamento de vários problemas, todos articulados entre si (Lebergott 1984). Um deles dizia respeito à questão se a terra deveria ser vendida diretamente ou através de intermediários (companhias de investimentos privadas). Inicialmente, optou-se por vender as terras às empresas de investimento, que as revenderiam com lucros para colonos interessados. As primeiras iniciativas nesse sentido revelaram-se grandes fracassos, pois, na opinião de Lebergott (p. 77), "Uma vez que o capital delas [as companhias de investimento] estava empatado na terra, elas não obtinham renda nenhuma até que a terra fosse vendida." Em razão disso, em 1785 o Congresso retomou sua prerrogativa sobre a venda das terras e optou por oferecêlas diretamente no varejo.

Escolhida a venda no varejo como mecanismo de disposição das terras públicas, restava por resolver um outro problema: estabelecer a que preço elas deveriam ser vendidas. $\mathrm{O}$ problema aí era definir se o preço da terra deveria ser determinado pelo livre jogo da oferta e procura ou ser fixado, administrativamente, pelo Estado. Se a opção fosse pela primeira possibilidade, se e quando o governo decidisse entrar no mercado vendendo, muito provavelmente o preço da terra cairia a patamares bastante baixos, dado o imenso volume de terras disponíveis. Isso certamente afetaria negativamente o valor das terras já apropriadas por proprietários individuais ou empresas de investimento. Além disso, com preços baixos, as receitas das vendas das terras pelo Estado poderiam vir a ser irrisórias, num momento em que o jovem Estado norte-americano necessitava de recursos financeiros para afirmar-se sobre o território que se expandia velozmente para o Oeste. A opção foi pela segunda possibilidade, com a fixação administrativa e não de mercado para o preço da terra. Administrativa porque foi feita pelo Congresso na forma de lei, que fixou o valor de US\$ 2 o acre para todas as terras, valor bem acima do praticado à época pelo mercado. 
Um preço único no patamar mencionado foi justificado porque elevaria as receitas do novo governo provenientes, na época, da venda de terras. Ademais, acreditava-se que essa medida reduziria os custos administrativos de avaliar-se a imensidão de terras disponíveis à venda e o tempo poupado para fazê-lo. Adicionalmente, pensava-se que esta medida evitaria a especulação com terras, pois seria preciso que o especulador imobilizasse muito recurso em terras para obter algum retorno.

Além do preço elevado, a legislação estipulava, tentando condicionar a demanda, quantidades mínimas de terra a serem compradas: 320 acres até 1804,160 acres até 1811 e 80 acres a partir de então. Interpretando a intencionalidade dessas duas medidas, Gates (1989:56) observou que

\begin{abstract}
$\mathrm{Na}$ verdade, esperava-se que as primeiras compras de terras fossem feitas por capitalistas, e não para melhoria e desenvolvimento, mas para especulação. Pequenas aquisições não eram permitidas e durante o período da Confederação foram oferecidas condições especiais para grandes e influentes compradores. Os termos do crédito governamental permitiram aos especuladores possuir grandes quantidades de acres com apenas pequeno pagamento. Durante esses intervalos, quando a competição por terras era ativa, como após 1815 , eles podiam revendêlas a outros especuladores ou aos verdadeiros colonos a preços mais altos, novamente a crédito. O crédito então, em períodos de rápidas mudanças, foi uma benção para o especulador, que poderia possuir de 3 a 20 vezes tanta terra quanto ele teria meios para comprar de uma só vez.
\end{abstract}

Embora orientadas, para favorecer o grande comprador, essas medidas não impediram que os pequenos colonos delas se beneficiassem marginalmente. As condições de oferta do crédito para o colono no início do século XIX eram as seguintes: 1/20 deveriam ser pagos à vista no dia da venda, $1 / 4$ em quarenta dias e o saldo em até quatro anos. Um período mínimo de permanência na terra ( 5 anos) era garantido ao colono, antes que os inadimplentes perdessem suas terras. Segundo Gates (1989:56)

O crédito foi instituído para auxiliar o intrépido pioneiro e sem dúvida ele capacitou a muitos o acesso e, com a leniência demonstrada aos inadimplentes, permitiu-lhes no fim conseguir o título. De outro lado, ela encorajou homens de poucos meios a comprar em excesso e contribuiu em grande medida para a grande orgia de especulação na qual áreas inteiras do domínio público foram convertidas em propriedades privadas e dedicadas ao uso improdutivo.

O preço da terra somente caiu em 1820 , para cerca de US\$ 1,25 o acre e permaneceu neste valor até 1862. Na opinião de alguns analistas (Gates, 
Lebergott, Clawson) a existência de um preço único para terras tão heterogêneas cobrou um preço alto em termos de ocupação do solo: induziu a ocupação desordenada do domínio público.

A forma de compra da terra foi mais um dos problemas que a política de terras no período teve de lidar. O dilema era o seguinte: a terra deveria ser paga a vista ou financiada pelo crédito? Conforme comentado anteriormente, a princípio optou-se pelo financiamento público à aquisição de terras ${ }^{10}$. Essa opção porém durou até $1818 / 19$, ano de profunda crise financeira, que praticamente eliminou o crédito governamental. $\mathrm{O}$ abandono definitivo do sistema de crédito aconteceu em 1819. Diante da incapacidade dos colonos que compravam terras públicas a crédito de honrar compromissos e da pressão por perdão da parte de grupos politicamente influentes, foram aprovadas uma série de leis de anistia aos devedores. Mesmo assim, este curto período de crédito público foi suficiente para induzir movimentos especulativos na negociação de terras.

Outro problema foi o de como evitar a migração de colonos em direção ao Oeste. $\mathrm{O}$ temor era que migrações massivas intensificassem os conflitos entre brancos e índios e, também, aqueles vinculados à titulação das terras, envolvendo, em geral, aqueles que adquiriram terras via compra e os posseiros previamente estabelecidos. Várias leis e medidas governamentais foram tentadas. Tudo em vão. A migração aumentou significativamente, fortalecendo a representação política dos Estados do Oeste, que lutaram a favor de uma política de terras abertas.

Um último problema dizia respeito aos conflitos regionais suscitados pela expansão para Oeste. A resistência política à distribuição incondicional de terras veio principalmente dos Estados do Leste e do Sul e sua ação anti-reformista foi responsável, em grande medida, pelo atraso na aprovação da Homestead Act.

$\mathrm{Na}$ verdade, temia-se pela prosperidade dos velhos estados, uma vez que as terras a Oeste prometiam maiores rendimentos. Os fazendeiros do Leste temiam igualmente pela perda de capitais, já que o preço de suas terras cairia; receavam também a elevação dos salários no Leste como forma de reter a mão-de-obra, que de outra forma migraria para o Oeste. A solução destes conflitos regionais veio somente depois da Guerra Civil, que provocou uma nova divisão inter-regional do trabalho, na qual os estados do Leste se especializaram na produção manufatureira, no comércio e nas finanças.

Aos poucos a política de terras com ênfase na receita pública foi sendo abandonada. Seus resultados sobre a receita governamental foram bastante discretos, contrariamente ao que previam os legisladores que a

10 Em 180o, os termos de concessão de crédito para compra de terra eram os seguintes: 1/4 do valor deveria ser pago em 40 dias, outro quinto em 2 anos e o restante em quatro anos (Lebergott 1984:80). 
elaboraram ${ }^{11}$. Mais importante, cedendo a pressões de vários e diferentes grupos de interesse, o Estado aprovou, durante o período 1819-62, leis que ofereciam aos colonos e especuladores o acesso à terra das mais diferentes formas: venda preferencial, anistia aos devedores e doações compensatórias. Ilustrativo disso foram as várias leis de preempção, a primeira das quais aprovada em 1830. Elas estabeleciam o direito preferencial de comprar 160 acres de terras não demarcadas antes de outros interessados ao colono que trabalha a terra. Ainda, entre 1847 e 1855 novas leis concederam terras entre 40 a 160 acres a veteranos de guerra. Os Certificados de Concessão Militar ofereceram-lhes um total de 61 milhões de acres, a maior parte deles revendidos pelos beneficiados a especuladores. Outro exemplo foi a aprovação, em 1850, da Lei das Terras Pantanosas, que autorizava a doação aos estados de terras pantanosas ou charcos na esperança de que esses fizessem investimentos de drenagem. Através desta lei foram transferidos da União para os estados cerca de 64 milhões de acres, a maioria repassada por vários caminhos a especuladores.

Esses e outros eventos sinalizaram claramente uma mudança na política de terras, que passou a caminhar paulatinamente, embora com muitas resistências dos Estados do Sul e do Leste, no sentido da distribuição de terras. Conforme observou Gates (1989:68)

As amplas políticas de distribuição de terras públicas foram baixadas por volta de 1830. Não houve mais restrições ao tamanho das compras; na verdade, os escritórios da terra davam preferência na ocasião aos grandes compradores: suas compras poderiam ser realizadas mais facilmente que a de numerosos pequenos compradores, e as taxas eram maiores. Direitos de pre-empção eram dados a posseiros de tempos em tempos; quando estes não eram concedidos, os posseiros protegiam seus "direitos" utilizando associações de reivindicação. Doações eram feitas somente a pessoas que residiam em terras estrangeiras que foram adquiridas pelos Estados Unidos. O crédito não foi mais oferecido após 1820, mas os posseiros frequentemente tinham um ano ou mais de uso livre da terra antes que tivessem que comprá-la. Os esforços para controlar ou fazer assentamentos compactos no Oeste foram abandonados, os índios estavam sendo aniquilados. A liberalidade do sistema retirou pessoas das partes mais antigas do país e da Europa para o novo Oeste, que estava crescendo a passos rápidos.

11 Conforme Clawson (1951:62) curiosamente, este sistema de venda de terras para gerar receita pública nunca produziu qualquer quantidade importante de receita, a despeito da seriedade com a qual ela foi debatida e considerada pelo Congresso e o público.(...) a receita das vendas de terras foi virtualmente nenhuma pelo menos até 1800 . Foi somente a partir de 1809 que a receita das vendas de terras públicas atingiu 5\% das receitas totais do Estado, e somente em 1814 atingiram 10\%. Daquela data até 1855 elas atingiram em média $10 \%$ da receita total. 


\subsection{A política de terras distributivista}

Parece paradoxal que o abandono do mercado como base da política de terras dos EUA tenha coincidido com a vitória das forças econômicas e políticas capitalistas de viés industrialistas após a Guerra de Secessão. O paradoxo deixa de existir, contudo, se tivermos em mente que a transição de uma para outra política não foi tão abrupta nem radical como se poderia inicialmente imaginar, expressando uma solução de compromisso entre a necessidade de manter o caráter mercadoria da terra e o ideal agrarista da pequena propriedade agrícola familiar. A nova lei de terras de 1862 foi o coroamento de iniciativas anteriores orientadas para franquear o acesso ilimitado à terra. A lei estabelecia que qualquer cidadão de 21 anos poderia adquirir a propriedade de uma área de terra pública já demarcada de até 160 acres (1/4 de secção), desde que nela morasse por cinco anos e a ela incorporasse melhorias.

Como vimos, desde 1819 amplas forças políticas, econômicas e sociais tentavam redefinir a política no sentido de permitir o acesso gratuito ao maior número de colonos interessados em cultivar a terra. Todavia, somente em 1862 uma legislação como a Homestead Act pôde ser aprovada e implementada. A resistência política do Sul estava sendo eliminada com a iminente derrota militar na Guerra Civil ${ }^{12}$; os Estados do Leste haviam avançado bastante na constituição de estruturas econômicas e institucionais favoráveis à industrialização e à expansão capitalista; e, finalmente, o Oeste aparecia para muitos, não apenas potenciais colonos, como a materialização do sonho jeffersoniano de uma sociedade livre e democrática assentada na agricultura familiar.

Tem sido comum superestimar os efeitos distributivos dessa lei, imputando-lhe uma radicalidade (em termos de distribuição de terras) que foi menor do que aquela efetivamente verificada. A Homestead Act não foi tão radical quanto se imagina, uma vez que não eliminou nem ofuscou a importância do mercado na definição da política de terras (Shannon:1945). Isto é importante porque embora a Homestead Act tenha marcado uma guinada na política de terras norte-americana, os mecanismos de mercado (venda de terras públicas) continuaram funcionando paralelamente. Conforme Gates (1996:42-3)

Que a receita não foi abandonada como um traço básico da política de terras do governo é demonstrado pelo fato de que os beneficiários com terras, desejosos de expandir sua propriedade para além dos 160 acres que eles poderiam adquirir pelo direito de desenvolvê-las, tinham a

12 Conforme Veiga (1991:60): "A promulgação da famosa Homestead Law, que procurava facilitar a distribuição de lotes de 160 acres $(64,75 \mathrm{ha})$, ocorreu em 1862, quando a rebelião do sul deu maioria no Congresso ao jovem partido Republicano, emanação dos meios industriais e financeiros do nordeste, francamente partidários da free land". 
escolha de comprar pedaços adicionais de ferrovias, Estados ou territórios - ou do governo federal se estivessem em áreas onde a terra tinha sido autorizada para venda em quantidade ilimitada. De fato foram vendidas mais terras governamentais entre 1862 e 1891 do que titulados beneficiados bem sucedidos da Homestead entre 1862 e 1891 . Ou, posto de maneira diferente, o governo obteve das vendas de terras públicas nos 60 anos que se seguiram à adoção da Homestead Act uma soma muito maior (US\$223.000.00o) do que nos primeiros anos da sua administração de terras (US\$ 186.000.000).

Outra evidência do caráter moderado da Homestead Law foi dada por Clawson, que calculou o montante de terras públicas transferidas a particulares conforme o tipo de acesso. O Quadro 1 apresenta os dados do autor.

\section{QUADRO 1. FORMAS DE DISTRIBUIÇÃO DAS TERRAS PÚBLICAS DO GOVERNO FEDERAL NORTE-AMERICANO}

\begin{tabular}{|cc|}
\hline Tipo de acesso & Acres ( em milhões) \\
\hline Homestead & 285 \\
Doações aos estados & 225 \\
Doações às empresas ferroviárias & 91 \\
Vendas e outras disposições & 430 \\
Total & 1.031 \\
\hline
\end{tabular}

FONTE: elaboração do autor a partir de Clawson (1951).

O quadro mostra que o mercado (a compra e venda) foi o instrumento mais importante de acesso à terra pública, respondendo por mais de $41 \%$ do total de terras. Impressiona a quantidade de terras doadas às empresas ferroviárias, que revenderam grande parte delas a colonos e outros agentes privados, fortalecendo a relevância do instrumento de mercado como alocador das terras públicas. As aquisições dos homesteadears corresponderam a 27,64\% de todas as terras do Estado.

Embora a política de terras tenha buscado o caminho do compromisso entre as duas tendências antes referidas, não se deve por isso subestimar sua realização: ela de fato permitiu o acesso a terra a um número bastante significativo de famílias, que de outra maneira não poderiam jamais vir a ser produtores agrícolas. Da mesma forma, ela ofereceu as condições para que posteriormente se consolidasse, na paisagem rural norte-americana, o predomínio da agricultura familiar. Em suma, não restam dúvidas de que as políticas de terras norte-americanas, com suas tendências aparentemente contraditórias, seus avanços e recuos, foram um instrumento efetivo de democratização da terra e regularização fundiária. 


\subsection{Instituições: o federalismo, a Northwest Ordinance e o Escritório Geral da Terra}

As análises sobre as políticas de terra dos EUA não têm dado o relevo devido ao papel das instituições na sua materialização. A legislação e sua efetiva (ou quase) aplicação, a qualidade das organizações públicas e privadas, o papel das associações comunitárias e dos grupos de interesse, o tipo de federalismo instituído jogaram um papel importante no sentido de - no contexto da expansão do capitalismo norte-americano e da afirmação do Estado Nacional - moldar um tipo de compromisso entre as prerrogativas do mercado (produção e acumulação de mercadorias, inclusive a terra) e as aspirações político-sociais de erigir-se uma sociedade democrática e igualitária com base na pequena propriedade agrícola familiar (o ideal jeffersoniano). A materialização desse compromisso somente foi possível graças à existência de instituições que auxiliaram na soldagem de objetivos aparentemente tão dessemelhantes.

Qualquer análise das instituições que auxiliaram na definição e execução da política de terras dos EUA deve fazer referência ao federalismo norte-americano. A forma de Estado que foi aos poucos se constituindo após a Independência, e depois na esteira das anexações, compras e conquistas do imenso território que são hoje os Estados Unidos, teve um papel determinante nos dois períodos da política de terras dos EUA. Não é nosso objetivo aqui discutir em profundidade a natureza e particularidades desse federalismo, basta referir que as relações entre União e Estados, pelo menos na questão da terra, pautaram-se por negociações que envolveram, do lado da União, a garantia do pagamento dos débitos com soldados e fornecedores privados e segurança aos seus cidadãos contra potenciais agressores externos e, do lado dos Estados, a renúncia a uma série de prerrogativas, entre as quais a maior parte das terras, que passaram para a União. Desse modo, na gênese do Federalismo norte-americano os Estados cedem parte fundamental dos seus direitos de propriedade da terra para a União, oferecendo a oportunidade para que esta centralizasse recursos fundiários para implementar sua política de terras. Conforme Clawson (1951:19)

Houve um sentimento forte no sentido de dar à nova Nação alguns ativos tangíveis com os quais assegurar o pagamento das suas dívidas e zelar pelo valor da moeda. Em 1781, Nova York cedeu-lhe direitos a 200.000 acres no que é hoje o nordeste da Pennsylvania. Em 1784, a Virgínia cedeu-lhe direitos a uma imensa área, mas reservou títulos, contudo, sobre certas áreas para honrar doações de terras prometidas aos soldados. Em 1785, Massachusets concedeu sem reservas seus direitos às terras a Oeste. Nos anos seguintes Connecticut cedeu a maioria das suas terras à nova Nação, mas reservou uma área de quase 4 milhões 
de acres na divisa com Ohio, ao longo da margem do lago Erie. Parte dessas terras ela doou a alguns dos seus cidadãos que sofreram perdas na Revolução e parte ela vendeu.

A citação acima ilustra uma parte das intensas negociações de terras que envolveram a constituição da Federação. Em geral, veio dos estados o estoque de terras que permitiu à União uma fonte de renda e as condições para instrumentalizar a política de terras. Além disso, os Estados concordaram em abrir mão de algumas prerrogativas sobre as terras que lhe restaram, tais como: 1) a não-discriminação na tributação dos proprietários absenteístas; 2) a cessão à União dos direitos sobre toda a terra não apropriada dentro das suas fronteiras e 3) que não cobrariam impostos das terras do governo federal. À medida, contudo, que o território se expandia e novos Estados eram agregados à Federação, um volume razoável de terras fluiu da União para os Estados. Aos primeiros Estados que se integraram à União foram concedidas doações de terras equivalentes a $3 \%$ da área total do Estado, valor que subiu posteriormente para $6 \%$ e $11 \%$ a medida que novos Estados aderiam à União. Em muitos casos, em troca do ingresso à União, esta cedia 1/7 das suas terras aos Estados.

Em todo esse processo de negociação, contudo, a União jamais permitiu que os Estados obtivessem o controle completo sobre as terras dentro das suas fronteiras, garantindo para si, por esse meio, a possibilidade de elaborar e implementar uma política nacional de terras. A importância do federalismo é a de que ele - ao transferir as terras para a União - permitiu a centralização necessária para viabilizar uma política nacional de terras, isto é, uma política que superasse os interesses regionais e locais e dispusesse das terras públicas conforme interesses mais gerais. Nesse aspecto a experiência norte-americana foi totalmente diferente da brasileira.

Um dos aspectos mais importantes de uma política de terras que objetiva a transferência de domínio público para o privado é a identificação e demarcação da área de propriedade do Estado. Nesse sentido, a Northwest Ordinance (Ordenação do Noroeste) ${ }^{13}$ é fundamental, pois instituiu o método pelo qual as terras públicas seriam demarcadas e divididas para que pudessem ser transferidas a proprietários privados, assegurando-lhes direitos legais claros sobre os lotes de terra. Na verdade a Northwest Ordinance fez mais do que isso: ela também eliminou da legislação os resquícios de formas de propriedade não tipicamente capitalistas, ao pôr fim ao sistema de primogenitura, que transmitia a terra apenas ao filho primogênito, e dar cabo de uma série de leis que restringiam a compra e venda de terra, herança do sistema feudal da ex-

13 A Norhwest Ordinance foi a legislação federal editada em 1875 que definiu o modo como as terras públicas foram divididas e demarcadas para a venda a particulares. 
metrópole inglesa (Krall 2002). Instituir a propriedade privada plena da terra foi um ato ao mesmo tempo de afirmação da autoridade do Estado (contra as formas antigas de propriedade sobre as terras dos indígenas e das relações feudais) e de viabilização de condições institucionais para a expansão das relações mercantis (a definição dos direitos de propriedade para que ela possa ter status de mercadoria).

Aprovada em 1785, a Northwest Ordinance estabeleceu o alicerce de todas as políticas de terra dos EUA ao oferecer-lhes um instrumento efetivo para extremar as terras públicas das particulares e registrar uma e outra. A Ordenação instituiu o sistema retangular de demarcação, que foi minuciosamente descrito por Clawson (1951) mais ou menos como se segue.

Para o levantamento de uma região particular sob esse sistema era escolhido um ponto inicial - muitas vezes o pico da montanha mais alta da região. Este ponto inicial era cuidadosamente marcado. A partir dele uma linha, chamada de meridiano principal, era traçada no sentido Norte-Sul. Outra linha, chamada linha base, era traçada no sentido LesteOeste a partir do mesmo ponto inicial. Partindo do ponto inicial e medindo do meridiano principal e da linha base, a região a ser demarcada era então subdividida em quadrados (chamados distritos) de 36 milhas quadradas $(6 \times 6)$. Os distritos foram traçados em direções cardinais em benefício da simplicidade, uniformidade e adaptabilidade. Teoricamente, o domínio público inteiro poderia ser demarcado a partir de um único ponto inicial. Na prática e por questão de controle de medida, novos pontos iniciais eram estabelecidos em locais estratégicos. Quando um assentamento começava em uma área distante daquelas já demarcadas, era estabelecido um novo ponto inicial para puxar a linha a partir da antiga. Uma parte básica da descrição legal de qualquer trato de terra incluído no sistema de levantamento federal é o nome do meridiano principal e do Estado.

Um distrito individual era identificado pela sua relação com o meridiano principal e a linha base da qual ela foi levantada. Isto era fácil porque os distritos eram dispostos em filas do Norte ao Sul a partir da linha base e em filas de Leste a Oeste a partir do meridiano principal. Para identificar qualquer distrito particular tudo que era necessário fazer era indicar em qual fila ele estava. Este sistema de distritos identificava cada pedaço de 36 milhas quadradas. Tal área inclui aproximadamente 23.040 acres, extensão muito grande para a maioria das transações com terra. Por isso, subdivisões dos distritos foram necessárias. Trinta e seis secções de uma milha quadrada foram estabelecidas. Elas foram numeradas de 1 a 36, começando do canto nordeste e indo para oeste para as secções de 1 a 6 , descendo uma fila a partir do leste para as secções 7 a 12 e assim por diante por todo o distrito. Dado o número da secção, 
qualquer um que fosse familiar com este método de demarcação e descrição de terras poderia pronta e rapidamente localizar um pedaço particular dentro de cada distrito. Divisões menores dentro de cada secção eram possíveis, nos casos em que a secção de 640 acres fosse muito grande.

Este sistema de demarcação era básico para os títulos de terra em todas as partes dos EUA que foram outrora domínio público. Foi nele alicerçado que posteriormente consolidou-se a imagem do homesteader competindo em confusas corridas pelos lotes de terra previamente demarcados. Essas terras demarcadas não só foram as bases sobre a qual títulos originais passaram do governo federal para pessoas e empresas privadas, mas têm sido, ainda hoje, a base também para a maioria das transferências de títulos de terra que aconteceram desde então.

A Norwest Ordinance instituiu a propriedade privada plena da terra nos EUA ao delimitar com relativa clareza e precisão os direitos de propriedade, primeiro do Estado e, depois, através das vendas de terra pública, dos particulares. Para que fosse eficaz, no entanto, a lei necessitou ser aplicada, gerenciada e aceita. A forma histórica como isso se deu foi através da criação de uma organização adequada para essa tarefa.

Antes de 1812, a gestão da política de terras - ou seja, sua demarcação e venda - envolviam diretamente o presidente da República e o Secretário de Estado, que deveriam assinar todos os títulos de propriedade emitidos. Quando o número de vendas aumentou, este esquema mostrou-se inviável. Para substituí-lo, em 1812 o Congresso criou o Escritório Geral da Terra (EGT), departamento subordinado ao ministério da fazenda (Treasury Department) que tinha como objetivos: 1) mapear e demarcar o domínio público; 2) fazer vendas e recolher a receita delas; 3) doar títulos. O Escritório tinha a estrutura apresentada na Figura 2.

FIGURA 2. O ESCRITÓRIO GERAL DA TERRA DOS EUA EM 1812

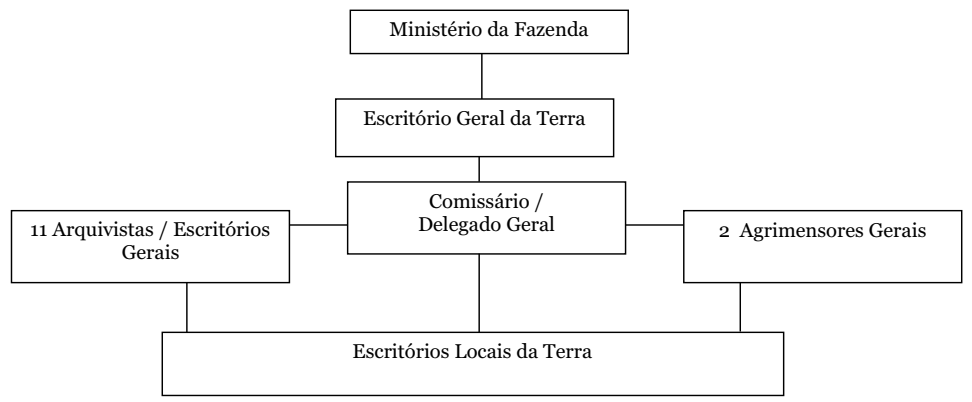

FONTE: Elaboração do autor, baseado em Gates (1989). 
O território e os estados eram divididos em distritos de terras, nos quais um Escritório Local de Terras operava como ramo do Escritório Geral de Terras. Cada escritório local empregava pelo menos três funcionários: o escrivão, responsável pelo livro das terras; o agrimensor, responsável pelo livro de registro de todas as terras vendidas, bem como da descrição das mesmas e o coletor, responsável pelo registro de todos os pagamentos recebidos da venda de terras e pelos livros de registro, que eram duplicatas dos do escrivão. Os funcionários dos Escritórios Locais de Terra recebiam um salário anual (US\$ 500) mais uma comissão de $1 \%$ das receitas das vendas para o escrivão e $1,5 \%$ para o coletor. $\mathrm{Na}$ verdade, a atividade de preparar a terra pública para venda era uma atividade que envolvia outros atores além dos que trabalhavam nos Escritórios Locais de Terras. Gates (1989:54-5) fez notar que

\begin{abstract}
Demarcar os distritos e limites, as secções e subsecções, marcar os ângulos, tomar notas sobre a formação das terras, da cobertura florestal, drenagem, minerais e outros fatos que poderiam ser úteis aos colonos foi uma tarefa que exigiu muitos agrimensores qualificados, lenhadores, sinaleiros e mateiros. Os contratos para demarcar eram dados a pessoas que, em casos notáveis, realizavam suas atividades de maneira irresponsável, traçando limites descuidadamente, marcando insuficientemente as coordenadas e fazendo sérios erros de cálculo. Muitos homens de fronteira possuidores de conhecimentos rudimentares de agrimensura asseguravam contratos ou subcontratos que o seu limitado conhecimento e experiência não lhes permitiam realizar de maneira adequada.
\end{abstract}

O mesmo autor observa ainda que muitos agrimensores, pela habilidade de avaliação e conhecimento da qualidade das terras que adquiriram, tornaram-se ora "olheiros" de terras a soldo de interessados em comprar terras, ora especuladores, grandes ou pequenos, que escolhiam as melhores terras que conseguiam identificar no seu trabalho de mapeamento, ora ainda agentes capacitados para registrar terras para capitalistas em parceria ou em pagamento por secção.

Essa estrutura expandia-se conforme aumentava a tarefa do Escritório Geral da Terra. Em 1821 havia 21 escritórios locais de terras, 36 em 1822 e 78 em 1860. Depois dessa data, contudo, o número de Escritórios Locais da Terra diminuiu paulatinamente, conseqüência do avanço e êxito do processo de demarcação e transferência de terras. Aparentemente, apesar das várias denúncias de desvios, favoritismos e imperfeições, o EGT estava bem aparelhado uma vez que, conforme Gates (1989:55)

Em 1820, 72.805.00o acres tinham sido mapeados em nove estados e 
territórios, dos quais 18.601.00o tinham sido vendidos. Ao longo de todo o século, a disparidade entre o número de acres averiguados e o número vendido continuou a aumentar.

\section{A política de terras no Brasil}

A política de terras no Brasil possui também dois momentos. Um primeiro, que durou de 1822 a 1850 , caracterizou-se pela ausência de regulação sobre a terra pública e pelo crescimento vertiginoso das posses. O segundo momento compreende o período posterior à aprovação da Lei de Terras (1850), caracterizado pela tentativa de implementação de uma efetiva política de terras que realizasse a necessária conversão do regime sesmarial em propriedade privada plena. Antes de analisar esses dois momentos é necessário comentar rapidamente o processo de apropriação de terras que antecedeu a Independência porque sua dinâmica será uma das heranças que condicionarão os períodos posteriores.

\subsection{Os antecedentes coloniais}

A política de terras no Brasil e seus efeitos somente podem ser compreendidos quando remetidos ao contexto do sistema colonial e da expansão comercial iniciada em meados do século XV na Europa. Conforme observou Silva (1996) é a inserção da colônia brasileira no antigo sistema colonial que determina a forma de estruturação da propriedade fundiária no Brasil. Isto significa que não foi o regime de sesmarias o determinante fundamental da estrutura de propriedade (latifúndiomonocultura-escravidão), mas os imperativos funcionais impostos à colônia pelo sistema colonial, isto é, gerar excedentes para a apropriação da metrópole.

Na verdade, a estrutura econômica e social da colônia teve de organizar-se de maneira a permitir o funcionamento do sistema colonial. Para viabilizá-lo foi necessária a introdução do trabalho escravo, de maneira que a atividade econômica colonial orientada para fora somente era compatível com esse regime de trabalho. De fato, dada a abundância de terras, o trabalho livre seria inviável porque este poderia transformarse rapidamente em proprietário de terras, produzindo para seu próprio consumo. Isso só seria evitado ao custo do pagamento de elevados salários, o que inviabilizaria a geração de excedentes coloniais. Ao mesmo tempo, o trabalho escravo deixou livre a apropriação de terras por parte do senhoriato rural. Essa foi, portanto, a gênese da estrutura fundiária brasileira. Para ser plenamente compreendida sua expansão e consolidação, deve levar em consideração, além da inserção na estrutura do sistema colonial, a instituição e a administração do sesmarialismo colo- 
nial, que materializou a política de terras do período colonial. Neste sentido, Silva (1996) destaca dois períodos. O primeiro, que vai da descoberta até o final do século XVIII, é caracterizado pela gratuidade e condicionalidade.

A gratuidade refere-se ao fato de que as concessões de terras da Coroa eram feitas gratuitamente ao donatário, que as devia distribuir. A condicionalidade, por sua vez, determinava que as terras concedidas ficavam condicionadas à sua ocupação e utilização produtiva. Em caso contrário a Coroa cancelava a concessão e retomava para si as terras (que depois redistribuía para outras pessoas). É possível notar que a forma de propriedade não era a propriedade plena, característica do capitalismo, uma vez que o princípio da condicionalidade limitava o uso plenamente livre dos direitos de propriedade da terra. A Coroa recomendava a distribuição de terras no tamanho adequado ao seu pleno aproveitamento, o que na prática não foi seguido. Isso porque havia dois problemas que dificultavam o controle da Coroa sobre a apropriação de terras na colônia.

Um dizia respeito à imprecisão das técnicas de identificação do tamanho e localização das sesmarias; o outro remetia à prática disseminada de compra e venda de sesmarias, num contexto em que, como se viu, a terra era doada sob condição pela Coroa. Ademais, em razão dos imperativos da colônia (gerar excedentes econômicos para a metrópole) a Coroa fez vistas grossas às deformações na apropriação territorial na colônia. Assim, nesse período, a apropriação territorial fez-se com bastante liberalidade, posto que a metrópole omitia-se em relação ao descumprimento da extensa legislação sobre a apropriação de terras na colônia.

O resultado foi a consolidação de um modelo de agricultura latifundiária, monocultora (produtos de alta rentabilidade no mercado externo, como o açúcar) e escravista (garantia de força de trabalho numa situação de abundância de terras). A apropriação extensiva de terra ocorria, ademais, devido às técnicas rudimentares aplicadas à agricultura, que rapidamente esgotavam os solos e obrigavam a busca de terras férteis.

No período que vai do final do século XVIII até 1822 iniciou-se uma nova fase do sesmarialismo colonial caracterizado pela tentativa da metrópole de retomar o controle da apropriação territorial na colônia. Ocorreu um progressivo movimento de centralização da administração pública em favor da Coroa. Caracterizando esse período foram tomadas as seguintes medidas:

1) o fim da gratuidade da doação com a obrigação dos concessionários de pagarem um foro. Conforme Silva (1996:49): 
Tendo em vista que o pagamento do foro não incidia sobre a produção, mas sobre as terras (ao contrário do dízimo), compreende-se que um dos objetivos visados pela metrópole era desestimular os sesmeiros a manterem sob seu domínio terras improdutivas;

2) fixação de limites para o tamanho das concessões. Segundo a mesma autora,

Data provavelmente de 1697 a primeira providência nesse sentido. Ordenava que se dessem sesmarias de três léguas de comprimento por um de largura. As legislações posteriores reafirmaram essa limitação, como as que encontramos em 1698, 1699, 1711, 1743 etc;

3) confirmação por el-Rei das concessões de terras.

Essas medidas, contudo, não surtiram o efeito desejado e o padrão de ocupação do solo permaneceu intocado.

\subsection{A estratégia Saquarema e a Lei de Terra}

O primeiro período da política de terras no Brasil compreendeu os anos 1822-1850, quando a urgência de constituição do Estado Nacional independente e a necessidade de consolidação e manutenção da unidade nacional dominou a agenda do Estado. Nesse período, nada foi feito para regularizar as terras públicas, constituindo um curioso caso em que o Estado abre mão de definir seu direito de propriedade da terra. A razão pode estar no fato de que o Estado, para levar a cabo as tarefas de pacificação e legitimação do novo Estado Nacional, tenha sacrificado a discussão da propriedade da terra, já que sua base social era constituída de grandes proprietários, a maioria deles posseiros e ocupantes em situação irregular. De resto, o desenvolvimento econômico interno não necessitava, naquele período, de nenhuma medida regulatória sobre a terra. Não convinha, portanto, hostilizar os proprietários com a questão da propriedade da terra. O resultado, no dizer de Silva (1996:81) foi que

No período entre 1822 e 1850 a posse tornou-se a única forma de aquisição de domínio sobre as terras, ainda que apenas de fato, e é por isso que na história da apropriação territorial esse período ficou conhecido como a "fase áurea do posseiro.

A partir dos anos 1840, contudo, as coisas começaram a mudar. A oposição interna e externa à escravidão aumentara, conflitos fundiários afloravam, os interesses políticos e econômicos ficaram mais comple- 
xos, ensejando a necessidade de retomar a questão da propriedade da terra. Ao longo dessa década, a questão da terra é retomada, gerando calorosos debates parlamentares e um radical (para a época e o contexto) projeto de lei (de 1843), que previa inclusive a criação de um imposto sobre a propriedade de terras. O projeto de lei de 1843 foi, contudo, abandonado, deixado sem aprovação, enquanto dominaram os gabinetes liberais. Em 1850, na vigência de um gabinete conservador, o projeto de 1843 é retomado e, após sofrer várias e importantes modificações, foi aprovado em 18 de setembro de 1850. Silva (1996) observou que a Lei de 1850 fazia parte da estratégia Saquarema ${ }^{14}$, que buscou forjar compromissos entre as forças políticas dominantes no sentido de assegurar uma transição lenta do trabalho escravo para o trabalho livre. A essência da transição era certificar-se, a partir do controle e direção do Estado central, que as frações das classes dominantes pudessem adaptar-se sem perdas ou ameaças significativas à inevitável abolição do trabalho escravo. Nesse sentido, encontra-se na sua raiz a necessidade de reforçar os fundamentos legais e de legitimidade do Estado e regularizar a propriedade da terra, viabilizando a transição lenta do trabalho escravo para o trabalho livre.

Aprovada em 1850 e regulamentada em 1854, a Lei de Terras objetivava: ordenar a apropriação territorial no Brasil; acabar com a posse; fazer um cadastro de terras; financiar a imigração; criar um setor agrícola de pequenos proprietários; tornar a terra uma garantia confiável para empréstimos e funcionar como um chamariz para a imigração.

Essa lei era necessária porque resolveria um problema que se manifestava com cada vez maior intensidade e dizia respeito aos conflitos que implicavam os proprietários particulares, que freqüentemente se envolviam em brigas familiares e crimes no campo por questões ligadas à delimitação das propriedades, dada a inexistência de direitos de propriedade definidos e garantidos. Desse modo era de supor que a Lei de 1850 ganharia o amplo apoio dos proprietários de terra e encontraria plena aplicação.

Não foi isso, contudo, o que aconteceu. Carvalho (1988) recupera com riqueza o processo de aprovação e implementação da lei, mostrando os interesses contrários e favoráveis a ela, assim como seus desdobramentos e resultados práticos. Nos limitaremos aqui a observar, valendo-nos do autor citado, o quão morosa e arrastada foi a aprovação e regulamentação da lei. Desde os primeiros trabalhos legislativos, iniciados por volta de 1842, até a regulamentação da lei, acontecida em 1854, transcorreu 12 anos. Tamanha demora espelhou as resistências de amplas frações dos grandes proprietários, de praticamente todas as regiões

14 No Império, eram chamados de Saquarema aqueles pertencentes ao partido Conservador ou com ele identificados, e de Luzias os adeptos do partido Liberal. 
do país, além de refletir alterações na conjuntura político-econômica, tanto interna quanto externamente.

Carvalho (1988) afirma que o interesse maior na aprovação da Lei tinha origem na província do Rio de Janeiro, onde a cafeicultura em processo de expansão parecia ameaçada pelas pressões internas e externas contrárias à escravidão. Para os fluminenses estava claro que o trabalho escravo tinha seus dias contados, necessitando substituí-lo pelo trabalho assalariado. Era nesse contexto que a lei de terras entrava: ela permitiria, entre outras coisas, financiar a imigração através da venda de terras, oferecendo ao imigrante, após um período de trabalho como assalariado, a perspectiva de estabelecer-se como pequeno proprietário de terras.

O problema era que as demais províncias não se beneficiavam de nenhum boom econômico semelhante ao experimentado pelo Rio de Janeiro, não se lhes afigurando com a mesma gravidade e urgência o problema da mão-de-obra. Na verdade, diferenças internas de interesse entre as elites agrárias das províncias fizeram com que todas, à exceção do Rio de Janeiro, se opusessem à aprovação da lei de Terras ou que sabotassem sua aplicação. Ademais, conforme lembrou Silva (1996), as elites provinciais viram na Lei a tentativa do governo central retomar as prerrogativas centralizadoras, às quais se opunham veementemente. Na opinião de Silva (1996: 175)

A análise dos dispositivos do regulamento de 1845 levam-nos a considerar que a fraqueza do sistema implementado era conseqüência da disputa existente no interior do Estado imperial entre as forças centrífugas, que lutavam pela predominância dos interesses provinciais, versus as forças que pretendiam concentrar o poder no centro, representadas sobretudo pela burocracia imperial e a cafeicultura do Rio de Janeiro.

O ponto de vista de Silva (1996) é convergente com aquele expresso por Carvalho. Para aquela autora, partiu dos grandes proprietários a maior resistência à aplicação da lei de terras. Essa resistência se explica porque ao se recusarem a demarcar suas terras (definindo seus direitos de propriedade) os fazendeiros ficavam livres para manter reservas de terras para apropriação futura. Essa atitude denotava o quanto o processo de apropriação fundiário predatório era extenso e, ao mesmo tempo, quão fraco eram o Estado e o ambiente institucional para imporem restrições à posse, uso e transferência da terra, revelando as imensas dificuldades que teve o Estado para instituir a propriedade plena ${ }^{15}$. A res-

15 Jones (1997) mostrou que o problema da regularização fundiária está na base da crise de legitimidade da propriedade rural no Brasil e observou que medidas para eliminá-lo reduziriam drasticamente os custos da Reforma Agrária no Brasil. 
peito da lei de 1850 , a autora afirma "Os analistas atuais ou contemporâneos acordam-se para afirmar que o mal não estava propriamente na lei, mas na sua aplicação prática" (Silva 1996:180).

Os efeitos práticos da Lei de Terra foram poucos. Ela regularizou as posses e as sesmarias dos proprietários que solicitaram a regularização; foi utilizada na jurisprudência quando surgiam dúvidas sobre a origem do título de domínio da propriedade; emitiu títulos de propriedade plena; ajudou muito modestamente o Estado na obtenção de recursos e encerrou definitivamente a existência da forma concessionária da propriedade. Os aspectos mais importantes da lei, contudo, não foram realizados. A lei não estancou a posse; não organizou um cadastro de terras, nem particulares nem devolutas; não vendeu lotes coloniais em grande escala; não disseminou a pequena propriedade familiar e não alterou o padrão de apropriação que existia desde tempos coloniais: grandes latifúndios, terra como reserva de valor, agricultura itinerante, limites fluidos entre propriedades.

É pertinente observar que as mudanças institucionais posteriores a 1850, como por exemplo, a Abolição da Escravidão (1888) e a Proclamação da República (1889), longe de questionar a dinâmica de apropriação de terras do período anterior, fez estimulá-la, principalmente no ambiente institucional erigido pela República Velha.

Como se sabe, a mudança institucional que resultou da alteração da forma de Estado de Monarquia para República implicou alterações importantes na relação entre o poder central e o das suas unidades constitutivas. À tendência à centralização que predominou no Império, sucedeu-se um forte movimento favorável à descentralização, delegando aos Estados e municípios uma imensa quantidade de poder, inclusive sobre a terra. A montagem do nosso federalismo, diferente do que aconteceu com os EUA, implicou, pois, no esvaziamento e enfraquecimento das prerrogativas da União, pelo menos no que diz respeito à questão da terra. Com a descentralização que se seguiu à República, a política central de terras deu lugar às várias e diferentes políticas dos Estados, que conseguiram não apenas autonomia, mas também o acesso ao patrimônio das terras devolutas ${ }^{16}$. A Constituição de 1889 transferiu aos estados o patrimônio fundiário das terras devolutas, incumbindo-lhes de identificar, demarcar e dispor delas como lhes aprouvesse.

O primeiro efeito dessa mudança foi o abandono de uma política nacional de terras, uma vez que os estados ganharam autonomia para legislar livremente sobre essa matéria. Em segundo lugar, a descentralização republicana ofereceu aos grandes proprietários/posseiros as condições

16 O artigo 64 da Constituição Federal de 1889 dizia que “...pertencem aos estados as minas e terras devolutas situadas nos seus respectivos territórios, cabendo à União somente a porção de território que for indispensável para a defesa das fronteiras, fortificações, construções militares e estradas de ferro federais" (Silva 1996:242) 
para influenciar poderosa e decisivamente sobre a política de terras dos Estados. A base da República Velha apoiava-se na forma política do coronelismo, um tipo de compromisso entre os interesses da grande propriedade e o sistema de representação política na qual o Coronel (que poderia ser ou não um proprietário fundiário) arregimentava massas de eleitores sujeitos ao seu mando e controle para votar no seu representante, esperando que este retribuísse com favores os votos conseguidos. Silva (1996:258) observou que "Nessa relação entre o poder privado local exercido pelos coronéis e o domínio da política estadual pelas oligarquias, residia a substância do compromisso coronelista”.

Conforme foi observado, os Estados obtiveram, com a Constituição de 1889, ampla autonomia para legislar sobre a questão da terra. Embora essa situação desse origem a uma multiplicidade de ações e políticas, Silva (1996) identificou três aspectos comuns a todas elas e que lhe conferiram uma certa unidade. O primeiro aspecto foi a adaptação da Lei de Terras aos interesses dos posseiros, através de sucessivas prorrogações nas datas limites dos processos de legitimação da terra. A Lei de 1850 estabelecera o ano de 1854 como o limite para o reconhecimento e legitimação das posses, passando, após esta data, ao domínio público aquelas que não fossem legitimadas. Depois de 1889 este dispositivo foi adaptado por todos os Estados e ganhou elasticidade com alguns deles ampliando a data limite para 1920. O segundo aspecto foi que em todos os estados a passagem do domínio público para o privado continuou a acontecer através de invasões e apossamentos por particulares, com a omissão quando não conivência dos governos estaduais. $O$ terceiro aspecto já foi anteriormente comentado e está vinculado ao aparecimento do coronelismo como fenômeno político típico da República Velha.

Tentativas mais recentes de políticas fundiárias que objetivassem restringir e definir os direitos de propriedade da terra, tais como a Constituição de 1946 e o Estatuto da Terra de 1964, mostraram-se inócuas como instrumento de intervenção efetiva na dinâmica de apropriação fundiária e na alteração da estrutura de uso e posse da terra no Brasil (Silva 1997).

Isso não significou a democratização do acesso à terra para a maioria. $\mathrm{Na}$ verdade, a grande propriedade, itinerante e predatória, avançava sobre terras públicas e ocupadas, expulsando, à medida do seu avanço, os pequenos proprietários e posseiros, incapazes de resistir ao poder (político e econômico) da grande propriedade. 


\title{
3.3 Instituições: o Federalismo brasileiro e a estrutura da Repartição Geral de Terras Públicas
}

A implantação da Lei de Terras teve de aguardar quatro anos, desde sua aprovação em 1850. O decreto imperial n. 1318 de 30 de janeiro de 1854 criou a organização responsável por materializar a política de terras: a Repartição Geral das Terras Públicas (RGTP).

O decreto definiu as atribuições da RGTP da seguinte forma, conforme esclarece Silva (1996:167).

\begin{abstract}
Essa repartição, chefiada por um diretor-geral das Terras Públicas, deveria dirigir e organizar a medição, descrição e divisão das terras devolutas e propor ao governo quais as terras que deveriam ser reservadas para a colonização indígena e estrangeira, quais as destinadas à fundação de povoações, à venda e à marinha. Deveria também promover a colonização nacional e estrangeira e organizar o registro das terras no domínio particular em todo o Império.
\end{abstract}

Sua estrutura pode ser visualizada na Figura 3. A RGTP estava subordinada ao ministério dos Negócios do Estado e era dirigida por um diretor-geral, nomeado pelo imperador. Cada província teria uma sucursal da Repartição Geral, subordinada ao presidente de Província e dirigida por um delegado do diretor-geral da Repartição nomeado, assim como este, pelo imperador. As províncias que possuíssem terras devolutas seriam divididas em distritos, para os quais era designado um inspetorgeral das medições que tinha a função "De dirigir os trabalhos de medição das terras devolutas (formando lotes de 121 ha) e a execução de mapas de cada um dos territórios medidos" (Silva 1996:168). 
FIGURA 3. A REPARTIÇÃO GERAL DAS TERRAS DO BRASIL

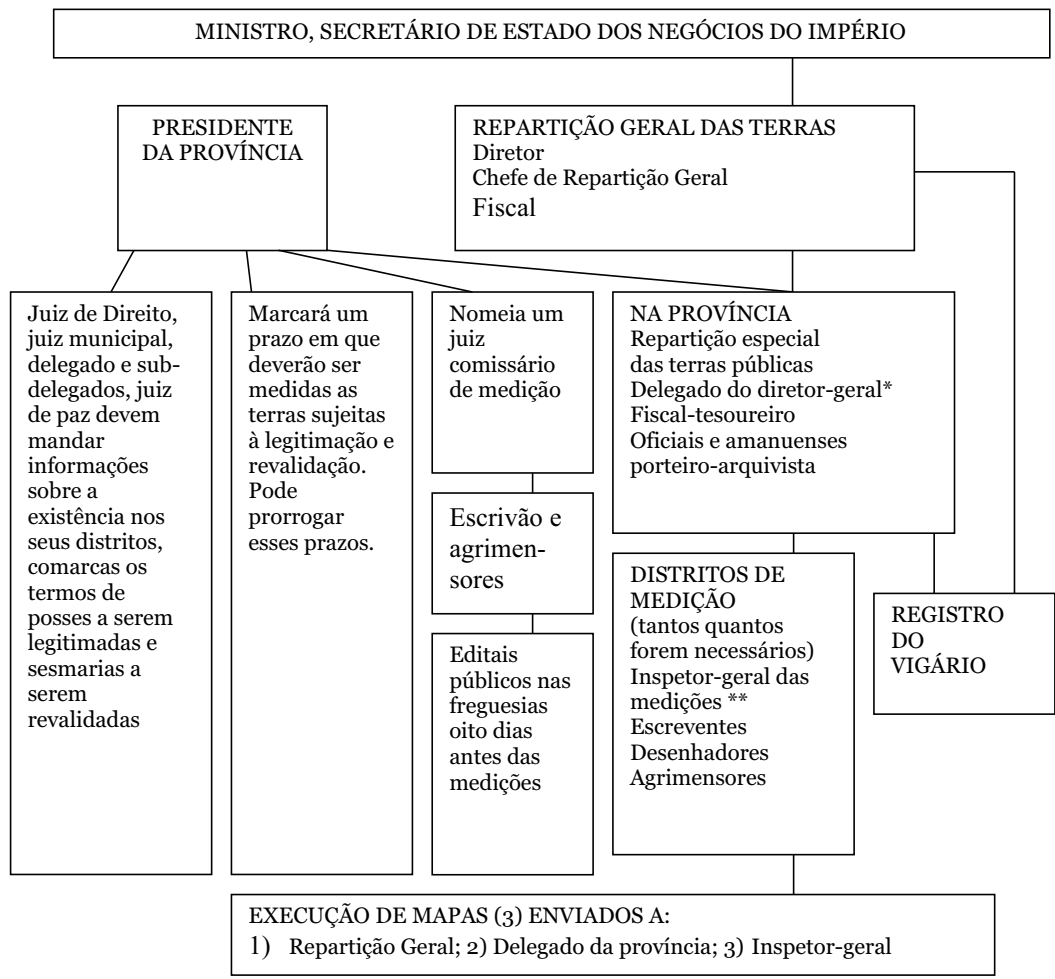

* Nomeado por decreto imperial.

** Nomeado pelo governo imperial sob proposta do diretor-geral.

FONTE: Osório Silva (1996:179).

O processo de medição e demarcação das terras particulares dependia diretamente do presidente de província, que deveria exigir que os juízes (de direito, municipais, de paz) e os delegados e subdelegados informassem sobre a existência de terras devolutas em suas jurisdições. De posse dessas informações, o presidente de província nomeava um juiz comissário de medição. A respeito deste último, Silva (1996: 168) afirma que

O juiz comissário era a figura central de todo o processo de regularização das propriedades particulares em situação ilegal, mas, detalhe importante, ele só entraria em ação a partir do requerimento dos particulares. Quer dizer, o processo de medição e demarcação das terras particulares para ser iniciado precisava da iniciativa destes, por 
intermédio de um requerimento ao juiz comissário pedindo a medição e demarcação das suas terras.

Era claro que a norma e as organizações encarregadas da aplicação da lei de terras não poderiam cumprir com seus objetivos. Seria impensável acreditar que os proprietários rurais brasileiros, a maioria em situação irregular perante a lei, iriam tomar a iniciativa da regularização, que significaria, além dos custos de demarcação, a limitação da área de terra que poderia ser apropriada, dada a tecnologia dissipadora de terras na época empregada. Em outras palavras, as instituições padeceram de ineficiências não apenas porque mal aparelhadas para esta função, mas fundamentalmente porque foram permeáveis às reações vindas dos proprietários de terra.

Nosso federalismo foi outro episódio característico. Ao contrário dos EUA, que nasceu uma unidade federada, o Brasil após a independência organizou-se enquanto nação, como Estado unitário e imperial, vindo a alterar esta situação somente no final do século XIX (1889), com a Proclamação da República. Na origem dessa mudança institucional esteve o desejo político de autonomia e descentralização das elites estaduais, desejosas de "liberdade" para viabilizar seus interesses regionais. Dominada por elites agrárias escravocratas, compostas de grandes proprietários (e ocupantes) de terras, a República brasileira funcionou institucionalmente como instrumento para subtrair ao governo central qualquer pretensão de estabelecer uma política nacional de terras. Sob seu controle, a terra pública continuou a ser apropriada extensivamente pelos grandes proprietários, que dissociaram, na maioria das vezes, a propriedade e seu uso produtivo. Daí porque com a República não apenas se conservou como se ampliou a concentrada estrutura fundiária do Brasil.

\section{Conclusões}

O texto procurou discutir de uma perspectiva comparativa duas experiências históricas de constituição da propriedade privada plena a partir do domínio público de terras. $\mathrm{Na}$ análise, a ênfase recaiu sobre o papel de duas instituições: a legislação de terras e o tipo de federalismo de cada país. No caso norte-americano, a política de terras buscou inicialmente garantir receita para o Estado recém constituído, através da venda em leilões públicos. Ela pressupôs a criação de instituições que cuidaram de identificar, demarcar e vender as terras de domínio público com relativa eficiência, dado o contexto da época. A Northwest Ordinance instituiu a propriedade privada, o método de demarcação e ofereceu a técnica que capacitou a formidável tarefa de definir os direi- 
tos de propriedade do Estado e dos particulares num contexto de expansão de fronteira e aprofundamento das relações mercantis na sociedade norte-americana. Importância semelhante teve o Escritório Geral de Terras.

O federalismo norte-americano foi outra das instituições. Na questão da terra, a forma como se estruturou a relação União-Estados foi fundamental para garantir à primeira condições materiais para a elaboração e execução de uma política de terras de caráter e impactos nacionais. Nos termos postos acima, as duas instituições constituíram-se de instrumentos de apoio de grande relevância para a expansão das relações capitalistas na ex-colônia.

No Brasil, a política de terras no período da independência na prática não existiu. O Estado deixou indefinida a situação da propriedade e tolerou a ocupação ilegal (posses) das terras públicas. As razões apontadas para esse estado de coisas foram a necessidade de priorizar a unificação e pacificação nacionais, relegando para plano secundário um tema que poderia complicar ainda mais as frágeis bases de legitimidade do Estado brasileiro. Uma política de terras efetiva somente foi elaborada no Segundo Reinado, pela necessidade de dar solução a vários problemas, entre os quais o do trabalho escravo, que deveria ser substituído pelo assalariado. A estratégia adotada, conhecida como estratégia Saquarema, cuidou de articular a disposição do domínio público para mãos privadas com o problema da mão-de-obra. Ela defendia uma transição gradual do trabalho escravo para o livre, por medo das conseqüências do radicalismo nesta matéria. Nesse sentido, a disposição do domínio público nasceu subordinada ao problema da mão-de-obra, ou seja, subordinada à dinâmica de uma forma capitalista de produção incipiente e pouco desenvolvida, que seria dependente por muitas décadas ainda do trabalho compulsório.

A estratégia Saquarema tentou forjar um compromisso de todo difícil de viabilizar: dotar de um arcabouço legal e institucional moderno (e mesmo radical, se pensarmos nas primeiras versões da Lei de Terras) e integralmente compatível com a propriedade privada plena exigida pelo capitalismo com relações de produção e forças produtivas ainda não amadurecidas para adaptar-se a ele. Isso se refletiu sobre as instituições encarregadas de viabilizar esse compromisso. A Lei de Terras virou "lei para inglês ver" e a Repartição Geral das Terras não conseguiu viabilizar nenhum dos objetivos que justificaram sua criação, ora por insuficiência e dubiedade da própria lei, ora pelo aparelhamento insuficiente de seus organismos subordinados, ora ainda pela resistência política dos proprietários fundiários. O resultado foi que, ao contrário da experiência norte-americana, as instituições não conseguiram impor-se no sentido de fazer aplicar a lei, resultando na continuidade do padrão exten- 
sivo de apropriação da terra e da ausência de direitos de propriedade completa e plenamente definidos.

O advento da República em nada mudou esta situação, contribuindo, inclusive, para agravá-la. O fato de se transferir para os Estados o poder de dispor das terras públicas significou não apenas uma reversão da tendência centralizadora que vigorou no Império. Ele concedeu poderes aos Estados para definirem, como quisessem, o modo como seria disposta ao domínio privado a terra pública. Na prática isso significou transferir aos interesses locais e regionais o poder sobre a questão fundiária. No contexto político da época, caracterizado pelo coronelismo, isto significou dotar os proprietários de terras e posseiros de grande poder de pressão, orientado na grande maioria das vezes para tornar sem efeito qualquer iniciativa de regulação pública das terras devolutas.

O fato de que ainda hoje, no começo do século XXI, as disputas pela propriedade e posse da terra sejam tão intensas e violentas quanto no passado são uma das heranças deixadas pela não aplicação da Lei de Terras. Mesmo em Estados tidos como “desenvolvidos”, como São Paulo, o problema fundiário é um dos mais graves, principalmente no Pontal do Paranapanema, onde são raras as propriedades privadas legais. Contudo, o aspecto mais negativo da estratégia Saquarema foi a de, intencionalmente ou não, impedir a constituição e desenvolvimento do setor de agricultura familiar, deixando ver o caráter fechado das políticas de terra no Brasil.

\section{Referências}

BASLÉ, Maurice (1993). "Mise em perspective de l'institutionnalisme de quelques économistes allemandes et américains." Économie Apliquée 4: 159-176.

BOUVIER-PATRON, C. (1993). "Les formes d'organisation des enterprises: limites de l'approche transactionnelle et genèse de l'inter-organisation." Économie Apliquée 4:7-40.

CARVALHO, José M. (1988). “A política de terras: o veto dos barões.” In CARVALHO, José M. Teatro das sombras: a política imperial. Rio de Janeiro: Vértice/IUERJ.

COLE, D. \& GROSSMAN, P.(2002). "The meaning of property rights: law versus economics?" Land Economics 78(3):317-30.

COSTA, Emília V. (1987). "Política de terras no Brasil e nos Estados Unidos." In COSTA, Emília V. Da Monarquia à República: momentos decisivos. São Paulo: Brasiliense, pp.139-61.

CLAWSON, Marion (1951). Uncle Sam's acres. New York: Dodd, Mead and Company. 
FLEMING, Grant (1999). "Social norms, economic behavior, and the law: a theoretical introduction.” Australian Economic History Review 39(3):16371 .

GATES, Paul W. (1989). Farmer's age agriculture, 1815-186o. Nova Iorque: M.E. Sharpe.

(1996).The Jeffersonian dream: studies in the history of America land policy and development. Albuquerque: University of New Mexico Press.

JONES, Alberto S. (1997). "Propriedade legítima da terra, grilagem e desapropriação: os falsos custos da Reforma Agrária.” In V Encontro NAIPPE/USP-ECEME/CPAex. São Paulo. Mimeo, pp. 1-20.

KRALL, L. (2001). "US land policy and the commodification of arid land (1862-1920)." Journal of Economic Issues 3(35):657-74.

(2002). "Thomas Jefferson's agrarian vision and the changing nature of property." Journal of Economic Issues 2(36):131-51.

LEBERGOTT, Stanley (1984). The Americans: an economic record. New York: W.W. Norton and Company.

PAULA, João A. (2002). "O mercado e o mercado interno no Brasil: conceito e história.” Revista História Econômica e História de Empresas 1:7-39.

PITELIS, C. (1994). "On transactions cost economics and the nature of the firm.” Économie Apliquée 3:109-30.

SHANNON, F. (1945). The farmer's last frontier. Nova Iorque: Rinehart \& Company, Inc.

SILVA, Lígia O. (1996). Terras devolutas e latifúndio. Campinas: Editora da Unicamp.

(1997). “As leis agrárias e o latifúndio improdutivo.” Revista São Paulo em Perspectiva 2(11):15-25.

VEIGA, José E. (1991). O desenvolvimento agrícola; uma visão histórica. São Paulo: Hucitec/Edusp.

WILLIAMSON, O. (2000). "The new institutional economics: taking stock, looking ahead.” Journal of Economic Literature 38:595-613.

Recebido em: 09 set. 2005

Aceite em: 21 abr. 2006 